Abbvie, Rorberto Giacomelli Consultant of: Pfizer, Novartis, Roche, Lilly, Celgene, Abbvie, Francesco Dieli: None declared, francesco ciccia Consultant of: Pfizer, Novartis, Roche, Lilly, Celgene, Abbvie, Giuliana Guggino Consultant of: Pfizer, Novartis, Roche, Lilly, Celgene, Abbvie DOI: 10.1136/annrheumdis-2021-eular.3814

\begin{tabular}{|l|l}
\hline POS0327 & INACTIVATION OF ALDEHYDE DEHYDROGENASE \\
& 3A2 INHIBITS FIBROBLAST ACTIVATION AND TISSUE \\
& FIBROSIS
\end{tabular}

X. Xu ${ }^{1}$, Y. N. Li ${ }^{1}$, C. W. Chen ${ }^{1}$, T. Trinh-Minh ${ }^{1}$, G. Schett ${ }^{1}$, J. H. W. Distler ${ }^{1}$.

${ }^{1}$ Friedrich-Alexander-University Erlangen-Nürnberg (FAU) and

Universitätsklinikum Erlangen, Department of Internal Medicine 3 -

Rheumatology and Immunology, Erlangen, Germany

Background: The aldehyde dehydrogenase (ALDH) superfamily composes a group of 20 enzymes that catalyze aldehyde oxidation. Within this enzyme family, ALDH3A2 stands out for its central role in the oxidation of long-chain aldehydes. Of particular interest, the substrates of ALDH3A2 include also profibrotic lipid mediators such as sphingosine 1-phosphate or leukotrienes, which have been reported to be deregulated in the context of SSc.

Objectives: We aimed to investigate the role of ALDH3A2 in fibrotic tissue remodeling in SSc.

Methods: Fibroblast-to-myofibroblast transition was analyzed by quantification of ACTA2/ $\alpha$ SMA, by assessment of stress fiber formation and mRNA and protein levels of type I collagens. ALDH3A2/A/dh3a2 siRNAs were employed to specifically knockdown ALDH3A2 in dermal fibroblasts both in vitro and in vivo. Overexpression of ALDH3A2 was achieved by ALDH3A2-pcDNA transfection. The role of ALDH3A2 was investigated in three different mouse models: Bleomycin- and cGvHD-induced dermal fibrosis as well as fibrosis induced by overexpression of a constitutively active TGF $\beta$ receptor I (TBRI ${ }^{\mathrm{CA}}$ ). Target genes of $A L D H 3 A 2$ in fibroblasts were identified by RNA sequencing

Results: The expression of ALDH3A2 was modestly reduced in dermal fibroblasts of SSc skin as compared to matched healthy controls. This reduction in ALDH3A2 expression was phenocopied by activation of TGF $\beta$ signaling, whereas selective inhibition of TGF $\beta$ signaling prevented the downregulation of ALDH3A2 in experimental fibrosis. ALDH3A2 overexpression promoted fibroblast-to-myofibroblast transition with increased levels of $\alpha \mathrm{SMA}$, enhanced formation of stress fibers and reduced collagen release. In contrast, knockdown of ALDH3A2 in dermal fibroblasts inhibited fibroblast activation and collagen release. Moreover, in vivo knockdown of ALDH3A2 in the skin of mice ameliorated dermal thickening, myofibroblast differentiation and collagen deposition in three different murine models of skin fibrosis: Bleomycin-induced skin fibrosis and sclerodermatous GvHD-as models of inflammatory stages of SSc and TBRI ${ }^{\mathrm{CA}}$-induced fibrosis as an inflammation-independent model of SSc. RNA sequencing of ALDH3A2-knockdown fibroblasts demonstrated that ALDH3A2 regulates the activity of a network of profibrotic developmental pathways including TGF $\beta$, Wnt, Notch, and Hedgehog signaling.

Conclusion: We demonstrate that ALDH3A2 regulates a network of profibrotic pathways to control fibroblast activation and tissue fibrosis. ALDH3A2 is modestly downregulated in SSc fibroblasts as result of an endogenous, TGF $\beta$-driven feedback loop. Although this modest downregulation is not sufficient to counterbalance the aberrant fibroblast activation in SSc, augmentation of this endogenous regulation by knockdown of $\mathrm{ALDH} 3 \mathrm{~A} 2$ demonstrates potent antifibrotic potential in experimental dermal fibrosis, thereby providing first evidence for ALDH3A2 as a target for antifibrotic therapies.

Disclosure of Interests: Xiaohan Xu: None declared, Yi-Nan Li: None declared, Chih-Wei Chen: None declared, Thuong Trinh-Minh: None declared, Georg Schett: None declared, Jörg H.W. Distler Consultant of: Actelion, Active Biotech, Anamar, ARXX, Bayer Pharma, Boehringer Ingelheim, Celgene, Galapagos, GSK, Inventiva, JB Therapeutics, Medac, Pfizer, RuiYi and UCB, Grant/research support from: Anamar, Active Biotech, Array Biopharma, ARXX, aTyr, BMS, Bayer Pharma, Boehringer Ingelheim, Celgene, Galapagos, GSK, Inventiva, Novartis, Sanofi-Aventis, RedX, UCB

DOI: 10.1136/annrheumdis-2021-eular. 1115

\section{POS0328 ENGRAILED 1 COORDINATES CYTOSKELETAL ORGANIZATION TO PROMOTE MYOFIBROBLAST DIFFERENTIATION AND FIBROTIC TISSUE REMODELING}

A. H. Györfi ${ }^{1,2}$, A. E. Matei ${ }^{1,2}$, M. Fuchs ${ }^{3}$, A. Rius Rigau ${ }^{1}$, X. Hong ${ }^{1}$, Z. Honglin ${ }^{4}$ M. Luber ${ }^{1}$, C. Bergmann ${ }^{1,2}$, C. Dees ${ }^{1}$, I. Ludolph ${ }^{5}$, R. Horch ${ }^{5}$, O. Distler ${ }^{6}$, G. Schett ${ }^{1,2}$, M. Kunz ${ }^{3}$, J. H. W. Distler ${ }^{1,2}$. ${ }^{1}$ Friedrich-Alexander-University Erlangen-Nürnberg (FAU) and University Hospital Erlangen, Department of Internal Medicine 3 - Rheumatology and Immunology, Erlangen, Germany; ${ }^{2}$ FAU Erlangen-Nürnberg and University Hospital Erlangen, Deutsches
Zentrum für Immuntherapie (DZI), Erlangen, Germany; ${ }^{3}$ Friedrich-Alexander University (FAU) of Erlangen-Nürnberg, Chair of Medical Informatics, Erlangen, Germany; ${ }^{4}$ Xiangya Hospital, Central South University, Department of Rheumatology, Changsha, Hunan, China; ${ }^{5}$ Friedrich-Alexander-University Erlangen-Nürnberg (FAU) and University Hospital Erlangen, Department of Plastic and Hand Surgery, Erlangen, Germany; ${ }^{6}$ Center of Experimental Rheumatology, University Hospital of Zurich, Department of Rheumatology, Zurich, Germany

Background: Engrailed 1 (EN1) is a homeodomain-containing transcription factor with essential roles in embryonic development. In most cell types, the expression of EN1 is restricted to embryonic development. However, under pathologica conditions, EN1 can be re-expressed to promote phenotypical adaptation. En1 is transiently expressed in the developing dermis of murine embryos in a distinct fibroblast lineage and silenced before birth (1). Former EN1-expressing cells give rise to a subpopulation of fibroblasts that has a high capacity for extracellula matrix production in adult murine skin. The role of EN1 in systemic sclerosis (SSc) was previously not explored.

Objectives: To study the role of EN1 in the pathological activation of fibroblasts in tissue fibrosis.

Methods: Bulk RNA-Seq and EN1 or SP1 ChIP-Seq were performed from cultured human dermal fibroblasts. The expression of EN1 was inhibited by siRNA. Cytoskeletal drugs paclitaxel, vinblastin and ROCK inhibitor (Y27632) were used to modulate the cytoskeleton in EN1 knockdown or overexpressing dermal fibroblasts. The role of EN1 in fibroblast activation was evaluated by functional experiments with EN1 knockdown or overexpression in standard 2D culture systems as well as in 3D skin equivalent models. The role of EN1 in skin fibrosis was further studied in En1 $1^{\text {fl/fl }} \mathrm{X}$ Col6Cre mice, with fibroblast-specific knockout of En1 in three complementary mouse models: overexpression of a constitutively active TGFß-receptor I $\left(\mathrm{TBRI}^{\mathrm{CA}}\right)$, bleomycin-induced skin fibrosis and TSK1 mice.

Results: Pathologically activated dermal fibroblasts from SSc patients express higher levels of EN1 compared with age and sex matched healthy individuals in the skin and in vitro. TGF $\beta$ induces EN1 expression in fibroblasts in a SMAD3-dependent manner both in cultured fibroblasts and in murine skin. Knockdown of EN1 prevents TGF $\beta$-induced fibroblast activation, whereas overexpression of EN1 fosters the pro-fibrotic effects of TGF $\beta$ with increased expression of $\alpha$ SMA stress fibers and collagen. RNA sequencing demonstrates that EN1 induces a pro-fibrotic gene expression profile functionally related to cytoskeleton organization and ROCK activation. In silico analyses of the promoters of En1 target genes coupled with siRNA-mediated knockdown demonstrated that EN1 regulates these pro-fibrotic target genes by modulating the activity of regulatory modules that contain transcription factors of the specificity protein (SP) family. Functional experiments with selective modulators of ROCK and of microtubule polymerization confirm the coordinating role of EN1 on ROCK activity and the re-organization of cytoskeleton during myofibroblast differentiation in both conventional culture systems and $3 \mathrm{D}$ skin equivalents. Consistently, mice with fibroblast-specific knockout of En1 demonstrate impaired fibroblast-to-myofibroblast transition, reduced dermal thickening and impaired collagen deposition in the $\mathrm{TBRI}^{\mathrm{CA}}$, bleomycin-induced and TSK1 models.

Conclusion: We characterize the homeodomain transcription factor EN1 as a molecular amplifier of TGF $\beta$ signaling in myofibroblast differentiation that coordinates cytoskeletal organization in a SP-dependent manner. EN1 might thus be a novel candidate for molecular targeted therapies to interfere with myofibroblast differentiation in fibrotic diseases.

\section{REFERENCES:}

[1] Rinkevich Y, Walmsley GG, Hu MS, Maan ZN, Newman AM, Drukker M, et al. Skin fibrosis. Identification and isolation of a dermal lineage with intrinsic fibrogenic potential. Science. 2015;348(6232):aaa2151.

Disclosure of Interests: Andrea-Hermina Györfi: None declared, Alexandru-Emi Matei: None declared, Maximilian Fuchs: None declared, Aleix Rius Rigau: None declared, Xuezhi Hong: None declared, ZHU Honglin: None declared, Markus Luber: None declared, Christina Bergmann: None declared, Clara Dees: None declared, Ingo Ludolph: None declared, Raymund Horch: None declared, Oliver Distler Consultant of: Actellion, AbbVie, Acceleron Pharma, Anamar, Amgen, Blade Therapeutics, CSL Behring, ChemomAb, Ergonex, Glenmark Pharma, GSK, Inventiva, Italfarmaco, iQvia, Medac, Medscape, Lilly, Sanofi, Target BioScience, UCB, Bayer, Boehringer Ingelheim, Catenion, iQone, Menarini, Mepha, Novartis, Mitsubishi, MSD, Roche, Pfizer, Georg Schett: None declared, Meik Kunz: None declared, Jörg H.W. Distler Consultant of: Actelion, Active Biotech Anamar, ARXX, Bayer Pharma, Boehringer Ingelheim, Celgene, Galapagos, GSK, Inventiva, JB Therapeutics, Medac, Pfizer, RuiYi and UCB., Grant/research support from: Anamar, Active Biotech, Array Biopharma, aTyr, BMS, Baye Pharma, Boehringer Ingelheim, Celgene, Galapagos, GSK, Inventiva, Novartis, Sanofi-Aventis, RedX, UCB

DOI: 10.1136/annrheumdis-2021-eular.1428 